International Journal of Child, Youth and Family Studies (2019) 10(2-3): 45-62

DOI: $10.18357 /$ ijcyfs 102-3201918852

\title{
MANAGING PAIN IN RESIDENTIAL CARE: A DEVELOPMENTAL ANALYSIS
}

\section{Heather Modlin}

\begin{abstract}
This article explores the presence of pain in residential programs for children and youth. The challenges associated with acknowledging and interpreting the behavioural manifestations of this pain - for the young people and for frontline practitioners - are discussed and interpreted through a constructivedevelopmental lens. The notion of the organization as a holding environment is reviewed, with a key focus on the role of the supervisor in absorbing the pain, providing emotional containment, supporting practitioners "where they are", encouraging reflection, promoting developmental growth, and maintaining a stable presence. Implications for the organization are reviewed.
\end{abstract}

Keywords: child and youth care, residential care, constructive-developmental theory, pain, pain-based behaviours, meaning-making

Heather Modlin PhD is the Provincial Director of Key Assets Newfoundland and Labrador, 495 Water Street, St. John’s, NL A1C 6E1. Email: heather.modlin@keyassetsnl.ca 
International Journal of Child, Youth and Family Studies (2019) 10(2-3): 45-62

The word care finds its origin in the word 'kara', which means to lament, to mourn, to participate in suffering, to share in pain. To care is to cry out with those who are ill, confused, lonely, isolated, and forgotten, and to recognize their pains in your own heart. To care is to enter into the world of those who are broken and powerless and to establish there a fellowship of the weak. To care is to embrace affectionately those who may be touched by hostile hands, to listen attentively to those whose words fall on deaf ears, and to speak gently with those who are used to harsh orders and impatient comments. To care is to be present to those who suffer and to stay present, even when nothing can be done to change their situation. (Nouwen, 2017, p. 193)

\section{The Manifestation of Pain in Residential Care: Pain-based Behaviours of Young People and Child and Youth Care Workers}

\section{Pain of the Young People}

Children and youth are often placed in residential care because the challenging nature of their behaviours makes it difficult for them to live in a family home. These behaviours can be aggressive, destructive, or disturbing (Frensch, Cameron, \& Adams, 2003; Whittaker \& Pfeiffer, 1994) and may include running away, self-harm, suicide attempts, verbal escalation, and physical assaults (Seti, 2007). Underlying the behaviours of young people in residential care are almost always histories of severe trauma, often in the form of one or more of physical, sexual, and emotional abuse, and neglect (Brendtro, 2004; Raychaba, 1993; van Beinum, 2008). These young people have experienced years of humiliation, degradation, chaos, threat, and fear; often they have been "incubated in terror" (Perry \& Szalavitz, 2006). The lifetime of hurt and pain that they carry with them is reflected in their behaviour (Anglin, 2002). As so eloquently stated by Crenshaw and Garbarino (2007, p. 160), "This deep reservoir of unrequited sorrow is the smoldering emotional underbelly to the violence." Unfortunately, front-line child and youth care practitioners are not always equipped to adequately respond to the behavioural manifestations of this underlying pain or to the emotional underbelly itself.

In Anglin's (2002) study of group care environments, he observed that there was a significant focus by the staff on the behaviours of the young people and not enough time spent on attending to the underlying feelings. Rarely "did careworkers acknowledge or respond sensitively to the inner world of the child" (p. 163). Anglin's findings are not isolated. In a study examining the high percentage of young people in the child welfare system that end up in youth corrections, Finlay (2003) described group homes as "gateways to custody" (p. 16) because of the pervasive focus on behaviours and punitive responses. Andre Cazabon's documentary Wards of the Crown (2006) relayed the experiences of several young people in Canada who had lived in group homes and subsequently transitioned out of care. A theme that emerged from all of the young people 
International Journal of Child, Youth and Family Studies (2019) 10(2-3): 45-62

about their experiences in group care was that the staff were unable to meet their emotional needs. A quote from one of the young people, which has been used extensively in promotional materials for the video, says "love is inappropriate in a group home".

\section{Pain of Child and Youth Care Practitioners}

While the pain of the young people is not always acknowledged, it is even rarer to acknowledge the pain of the staff. A significant percentage of individuals entering the child and youth care field carry with them their own trauma histories (Phelan, 2009) and are susceptible to being triggered by the behaviours and underlying emotional distress of the young people (Anglin, 2002).

Working in the midst of young people's distress and turmoil can take its toll on practitioners (Kahn, 2005) even in well-functioning teams (Anglin, 2002; Smith, 2009). Being exposed to the pain of individuals who have been victimized can leave practitioners at risk of developing secondary or vicarious trauma (Collins \& Long, 2003; Figley, 1995) and compassion fatigue (Seti, 2007), the symptoms of which can include extreme helplessness, victim blaming, emotionally distancing oneself from clients, over-identification with clients (Collins \& Long, 2003), anxiety, depersonalization, and pessimism (Osofsky, Putman, \& Leiderman, 2008).

In residential care, practitioners are not just exposed to the traumatic stories of the young people, they are exposed to the behavioural manifestations of their trauma as well. This adds an extra layer of complexity to the work that is often overlooked. As stated by Mattingly (1981), "No matter how skilled and sophisticated the worker, a kick in the shins, broken glasses, an insult, and a child's lack of progress are all assaults on self-esteem which threaten workers' perceptions of their helping ability" (p. 154). The expectation that child and youth care workers should always know what to do or how to respond in the most challenging of situations is referred to by AndersonNathe (2010) as "the myth of supercompetence". When practitioners experience moments of "stuckness", of not knowing what to do, they can become mired in self-doubt, shame, and feelings of inadequacy (Anderson-Nathe, 2010).

\section{Interpreting Behaviours and Acknowledging the Underlying Pain through a Constructive-Developmental Lens}

According to Anglin (2002), "the manner and degree to which the pain is responded to is one of the key indicators of the quality of care in a residence as experienced by the youth" (p. 168). It is critical, therefore, to have an understanding of why and how some child and youth care practitioners struggle with this task, and how they can be supported to respond more effectively. Why do some people in an organization appear to be constantly challenged by the job while others appear to more easily adapt to the demands placed upon them? Why do some practitioners "burn out" after only a few years in the field while others can work in the same environment for 20 years without experiencing any signs of burnout? 
International Journal of Child, Youth and Family Studies (2019) 10(2-3): 45-62

\section{Constructive-Developmental Theory}

One of the reasons, perhaps, why individuals are impacted differently by the same amounts of pain, in the same environment, may be related to their developmental capacity to let go of the pain, or to acknowledge it, or to recognize who owns the pain. Kegan's $(1982,1994)$ constructivedevelopmental theory is a useful lens through which to explore this further.

Constructive-developmental theory pertains to the ways in which we are constantly constructing and making meaning of our experiences. Our meaning-making is impacted by what we can see, are aware of, can take control over, and assume responsibility for (Kegan, 1982, 1994). As we develop in mental complexity, the balance between what we are subject to (embedded in) or can perceive as object (separate from self) continually undergoes a process of transformation. Constructive-developmental growth results in a more complex way of seeing, experiencing, and understanding oneself and the world (Kegan, 1982, 1994).

According to Kegan (1982), our meaning-making evolves progressively over the course of the lifespan through six qualitatively different constructive-developmental orders, or systems, with each order having its own distinct conception of the world. Two of these orders, socialized and self-authoring, are most prevalent in adulthood and will be briefly reviewed in the next section.

Socialized: At the socialized order of consciousness, the self is embedded in the relational realm. Individuals at this stage have developed the capacity to internalize and identify with the values and beliefs of their social surround and are able to subordinate their own interests on behalf of this greater loyalty. Individuals at the socialized order can engage in abstract thinking and are able to reflect upon their own needs, wishes, and interests through internal dialogue about themselves (Kegan, 1982, 1994). The views, opinions, and feelings of others can be brought into the self and they can put the needs of others ahead of themselves in order to remain connected (Strang \& Kuhnert, 2009).

The cost of this newly emerged developmental capacity, however, is that individuals with this meaning system are now subject to the expectations of others. Individuals at the socialized order do not just have relationships, they are their relationships. They view the world through their relationships and experience difficulty separating their own sense of self from the values, beliefs, and judgments of significant others (Kegan, 1982, 1994), who are perceived as sources of authority and co-constructors of the self (Popp \& Portnow, 2001).

Individuals with a socialized mindset have little tolerance for ambiguity (Popp \& Portnow, 2001). They need a clear sense of what is expected of them by others and feel a strong obligation to meet those expectations. Criticism is experienced as destructive to the self, because the orientation is toward a sense of belonging and connection (Kegan, 1994).

Self-authoring: Within the self-authoring meaning-making system, individuals move beyond being subject to the expectations of others and develop an autonomous self. They no longer 
International Journal of Child, Youth and Family Studies (2019) 10(2-3): 45-62

are their relationships, they have them. They have developed the capacity to differentiate the self from others, and others from their points of view. Individuals at the self-authoring order have the ability to regulate and evaluate their own values, goals, and interpersonal connections, and to transcend their own needs and those of others in accordance with their own personal, internal value system (Kegan, 1994). Influential others are no longer viewed as co-constructors of reality (Lahey, Souvaine, Kegan, Goodman, \& Felix, 1988) and those at the self-authoring order have developed the capacity to not assume responsibility for others' responsibilities (Drath, 1990).

\section{Dealing with Pain}

To cope with the emotional demands of the job, child and youth care workers are often provided with specific skills training, educated on the importance of self-awareness, and coached on the need to identify their "triggers" - primarily so that they will not get drawn into power struggles with the young people, or engage in counter-aggression. While this may be helpful, it presupposes that practitioners have the ability to identify their emotional response to the young person as separate from the young person - and this requires a particular way of knowing (and type of self-awareness) that they might not yet have developed. This speaks specifically to the possible impact of practitioners' developmental capacity on their experiencing of and ability to cope with their own and the young peoples' pain and pain-based behaviour. The capacity to manage pain may be related to the ability to think complexly. According to Kegan (1994), "the demand that we be in control of our issues rather than have our issues control us" (p. 133) is a demand for a self-authoring system of meaning-making.

Having the ability to transcend our own needs and focus on the needs of the young people requires that we first have the ability to separate our own needs from the needs of others. This is only possible, from a constructive-developmental perspective, if one has developed the capacity to do this - which would only occur when one is making meaning at the self-authoring order. Providing skill-based training on dealing with aggressive behaviour, for example, will not do much to address the fundamental problem if the demands of the job exceed one's developmental capacity to meet them. The concepts taught in training will simply be interpreted through the individual's existing logic.

\section{The Capacity to Reflect on, Dwell in, and Cope with the Pain of Self and Other: Developmental Influences, Interpretations, and Challenges}

The author conducted an exploratory study to look at whether Kegan's (1982) constructivedevelopmental theory may be a useful framework through which to view the practice of child and youth care in residential care and, in particular, the experiences of child and youth care workers in the context of their organizational environments (Modlin, 2018). One of the research questions asked participants to identify the primary challenges they experienced in their roles, and how they coped with these challenges. In this study, Kegan's constructive-developmental theory was used as an analytic tool to examine what the child and youth care profession is asking of practitioners 
International Journal of Child, Youth and Family Studies (2019) 10(2-3): 45-62

and to consider the fit, or misfit, between these demands and the mental capacities of the practitioners.

\section{Methodology}

The study was conducted in two stages. First, 99 participants completed the Professional Quality of Life Scale (ProQOL; Stamm, 2010), Work Environment Scale (WES; Moos, 2008), and Leadership Development Profile (LDP; Torbert \& Livne-Tarandach, 2009). The results of these measures are reported elsewhere (Modlin, 2018). From the initial pool, 18 participants (from five organizations, across three geographic regions) were selected for subject-object interviews (SOI). The SOI is specifically designed to elicit data on a person's "unselfconscious epistemology" (Lahey et al., 1988) or meaning-making capacity.

At the beginning of the SOI, participants were presented with 10 probe words intended to arouse strong thoughts and emotions. The probe words usually used are anger, anxiety, success, change, important to me, overwhelmed, proud, joy, challenged, and strong stand. To align the SOI with my research questions, I added the word "pain" and substituted the phrase "supported" for "strong stand". The words were presented on index cards, and participants were given 20 minutes to recall experiences conjured up by each word and write down their responses. These cards remained with the participants as a prompt to help them recall their experiences and were for their use only. I instructed participants to restrict the experiences to those from their current work environment. I began each interview by asking participants to select the card with which they would like to start. Once participants were finished talking about the content generated by this card, they were asked to select the next card. This process continued until the interview ended.

The goal of the SOI is to access the meaning-making structure underlying the participants' descriptions of their experiences. The fundamental question a subject-object analysis answers is: "From where in the evolution of subject-object relations does the person seem to be constructing his or her reality?" (Lahey et al., 1988, p. 10). The way to identify the underlying meaning-making structure during a SOI is to look for what people can and cannot take a perspective on. Specific types of questions have been developed to get at an individual's meaning-making structure during the SOI. These primarily include variations of "why" and "how" and questions that probe for extremes. The rationale for using these types of questions is that if the right questions are asked, one can find out, for example, "not why they are angry, but how the self must be constructed to experience the particular violation the speaker expresses" (Lahey et al., 1988, p. 290, underlined in original text).

The SOI has demonstrated construct validity as evidenced by "high degrees of consistency among alternative forms of the measure, different domains of experiencing, different test items and different psychological themes" (Lahey et al., 1988, p. 368). Inter-rater reliability in studies using the SOI has ranged from .75 to .90 (Kegan et al., 2001). Additionally, the SOI is capable of distinguishing 21 distinct epistemological positions and subsequently provides a more refined set of discriminations between any two stages than found in Kohlberg's Moral Judgment Interview or 
International Journal of Child, Youth and Family Studies (2019) 10(2-3): 45-62

the Washington University Sentence Completion Test (Lahey et al., 1988). The SOI has also demonstrated the capacity to capture gradual changes in an individual's constructivedevelopmental level in the expected direction over time (Lahey et al., 1988). Test-retest reliability has been demonstrated with correlations of .82 (Spearman coefficient) and .834 (Pearson's r), both significant at the .0001 level (Lahey, 1986). Inter-item consistency, with a correlation of .96, was documented by Villegas-Reimers (1988).

The SOI can only be used by researchers who are familiar with Kegan's constructivedevelopmental theory and trained in conducting and assessing SOIs. To address this, I completed a training course through Minds at Work with associates of Robert Kegan on conducting and scoring the SOI and engaged in additional individual sessions with one of the trainers. For this study, all interviews were scored by a second scorer.

A benefit of the SOI is that it can also be used to explore other areas during the interview and can be analyzed separately for content as well as structure. The SOI is ideally suited for research that seeks to explore participants' understanding in a particular area. I conducted an expanded version of the SOI to assess the meaning-making systems of participants, and also to gather information about how they cope with and experience the demands of the job and themselves in the job, and the influence of the organizational environment. Specific questions related to my areas of inquiry were embedded into the SOI and added to the end of the interview. Questions were designed to reveal the developmental differences in participants' experiences and the ways in which they made sense of these experiences.

Using the theory as a backdrop to the demands of the job provided new clues about potential sources of stress or difficulty for child and youth care workers that have not been previously identified or clearly articulated. There were differences in responses from participants who were at the socialized and self-authoring orders, and those who were transitioning between the two.

\section{Coping with Pain at the Socialized Order}

Individuals at the socialized order, when asked what were the most challenging aspects of their job, identified dealing with personal attacks from the young people, dealing with conflict, and dealing with ambiguity. Having to deal with young people who were angry and aggressive, and their associated pain, was identified as a very challenging aspect of their role. The biggest challenge was not, however, the physical act of dealing with these behaviours; it was the personal toll it took on the practitioners themselves. This is illustrated in the following dialogue, in which a participant talked about how depressing it was for her to be continuously threatened and sworn at by the young people:

And let's face it. You're cursed at a lot during the day and you're threatened a lot during the day, and you just don't feel very good. I mean, nobody wants to be cursed at. And after a while, it doesn't matter how many times that everyone says, "Oh, 
International Journal of Child, Youth and Family Studies (2019) 10(2-3): 45-62

don't take it seriously." If you've been cursed at for basically off and on for 12 hours or something like that, then it's pretty hard not to take it personally.

At the socialized order, individuals experience others as responsible for their own emotional reactions to them and are therefore captive to the other to change how they feel. An individual making meaning at the socialized order "cannot actually set things right by herself. Things will be set right when her inner psychological life is happier, but her inner psychological life is not an 'object' under her control" (Kegan, 1994, p. 122). For individuals with a socialized mindset a personal attack is not experienced as an interruption in the relationship, it is experienced as an interruption of the self (Kegan, 1982). Those who were socialized tended to focus on their own pain, although the pain of the young people was referenced in these conversations.

One of the participants, for example, expressed awareness that the young people's behaviour was "not about her". She tries to remind herself of this when she encounters a difficult situation. However, information she has received in training and from her supervisor about not personalizing the young people's behaviours has been interpreted through her socialized consciousness and often leaves her feeling worse. "Not personalizing" requires an emotional self that one has control over. At the socialized order, the self is embedded in the relational realm. Although this practitioner described valiant efforts to separate her reactions from the young people, it appeared that she cannot yet fully generalize to her practice what she has been taught. That generalization would require that she be able to step back and create some distance from the situation in which she is embedded (Berger, 2002).

The ultimate goal for individuals at the socialized order is to be "in alignment with ... a value creating surround" (Kegan, 1994, p. 171). Because those who are at the socialized order are embedded in the interpersonal, incidents and events that disrupt this alignment, such as being verbally attacked or mired in conflict, can be experienced by the socialized individual as a disruption of the self. Coping, therefore, requires much more than just exercising a set of skills. Coping with the many insults to self that socialized participants reported experiencing on the job requires a rebalancing of the relational equilibrium or a shift to a new way of knowing.

From a constructive-developmental perspective, individuals at the socialized order do not have the capacity to "regulate or subordinate" the claims others make on them; they are regulated by others (Kegan, 1994). When socialized practitioners are personally attacked by or engaged in conflict with a young person, for example, they see the young person as responsible for their (the practitioner's) emotional reaction to the attack. Individuals at the socialized order are unable to assume responsibility for their own feelings in response to a perceived insult. Instead, they would perceive the other as "making them mad", or "making them feel bad". "A person can only take responsibility for that which she actually is able to know responsibility can be taken" (Lahey et al., 1988 , p. 15). Without the personal authority to see that they can be responsible for their own reaction, and in control of their own feelings, socialized practitioners can be placed in an untenable 
International Journal of Child, Youth and Family Studies (2019) 10(2-3): 45-62

position — the very source of their distress, as they experience it, is also the source of their relief from the distress.

For the socialized individual, the "looming failure to preserve a collection of irreconcilable experiences may be experienced as a difficulty holding himself together" (Kegan, 1994, p. 167). This sets up a dynamic in which practitioners, without their own internal system that can mediate and regulate their experiences, may regularly encounter situations in which:

1. They feel like they are falling apart.

2. They have no way to put themselves back together.

The only viable coping options, from the perspective of the socialized individual, are assistance from an "other" that can serve to mediate the impact of the distressing event, or escape from the situation that is causing distress. Socialized participants discussed the urge to "check out" or "get away" when they were faced with situations that they found extremely challenging. This took many forms, one of which was disengaging from the young people. One participant, while talking about how she copes with young people swearing and yelling at her, expressed the following:

I guess the best thing to do is try to shut down as much as possible so that you're not offering anybody, you're not offering yourself as a target. And disengage and try to find something that's .... Appeal to your teammate. If it's a teammate that you know quite well, say, 'I can't do it with so and so today because they're just not responding to me. They don't like me or maybe they've never liked me period and they're just not giving me any slack at all. So can you deal with Johnny today and I'll deal more with the kitchen work?" or something like that.

This participant expressed that when she reached her "breaking point", she needed to get out. If she could not physically leave the home, which would be her preference, she would escape in her head or "mentally disengage". As she put it, "You look for whatever relief you can find." When asked what happened when she couldn't get any relief, she said, "Well, it's very draining. It's very soul draining. It's very disheartening. You can't find someone to relieve you. It's just really difficult, that's the only way I can describe it."

Other socialized participants also expressed that they felt overwhelmed when they did not get the opportunity to get away on their own. At the socialized order, individuals do not have the capacity to "fix" the damage done by another in the context of the relationship — this is outside of their control. Their only option to re-establish their relational equilibrium is in the hands of the other (usually a dysregulated young person). In the absence of this, they do what they have to do to escape the discomfort or "get relief". In some cases, this showed up in attempts to control the work schedule. Some participants tried to minimize the amount of time they would have to spend 
International Journal of Child, Youth and Family Studies (2019) 10(2-3): 45-62

with particular young people, preferring to work late evening or overnight shifts. Others used sick leave or vacation time. Denial was another form of escape, albeit psychological, described by some socialized participants. In describing how she deals with young people being aggressive towards her, a participant articulated that she does not personalize the behaviour, yet rather than deal with it directly, she pretends it didn't happen:

I've been called everything under the sun, but I guess you just go back the next day and you pretend like that didn't happen, because I'm very empathetic. So, if someone snaps at me or a young person loses his mind and calls me every name that they've ever heard I think, "Why? Did I do something?" Or was it, you know what? Their mom didn't show up that day, there was no call and no - I just try to get to the root of why and I guess not focus on, not make it personal. Because most of the time, it's not. So I just don't let that get me down and if you bring it back every shift, then you're never going to make any progress. You're going to be reliving that over and over and then you'll dwell on those things all the time.

Interviewer: Yes. How are you able to not bring it back?

Participant: Sleep helps me and even if it's in the back of my mind I just fake it, so I make it. I put on a happy face and ask how their day was and pretend like it didn't happen, unless they want to have a conversation about it or they bring it out and sometimes they'll apologize out of the blue. Sometimes they won't; sometimes just moved on like it never happened and that's okay too. I just don't know if there's a particular way or anything that I do cognitively to bring it back. I just don't.

While the notion of going into a new shift with a "fresh approach" is not reflective of any particular developmental order, it is the use of this approach to avoid dealing with unpleasant situations that reflects meaning-making at the socialized order. This participant was aware that she "should not personalize" the behaviour of the young person. However, for individuals making meaning with a socialized mindset, telling them not to personalize rude or vulgar comments from the young people can be "interpreted as an invitation to be colder, more callous, even indifferent, or to take up a position of greater distance in relation to the other" (Kegan, 1994, p. 126). The tendency to "pretend" the incident didn't happen illustrates this distancing. She does not bring up the incident, she waits for the young person to raise it - thereby keeping any potential resolution of the situation in the hands of the young person.

Participants at the socialized order generally described coping in one of two ways: by attempting to remove themselves from the distressing situation, or by relying on support from others. 
International Journal of Child, Youth and Family Studies (2019) 10(2-3): 45-62

\section{Coping with Pain at the Self-authoring Order}

Participants who were self-authoring identified being witness to the pain of the young people and the staff as a challenging part of their role. One participant shared the way in which front-line practitioners "take on" the pain of the young people:

I think a lot of that ... stuff I talked about, like the pain stuff is ... you did take a lot of this. You see their emotional suffering and ... I notice with empathy, you wanted to be careful. You don't want to just directly experience all that stuff to yourself.

This individual is able to reflect on the experience of absorbing the young people's pain with some distance from the relationship. He recognizes that he has control over how emotionally involved he can become, and the ability to extract himself as needed. Another self-authoring participant, while talking about the impact of seeing the young people in pain, relayed the following:

Pain ... I've been assaulted a lot in this job. Especially between the crisis response stuff. But pain, I think the first thing I thought of is the pain that you see on the kids' faces. How hard that is to watch. I think everyone that works in youth care is empathetic. It's almost like when they feel that pain, you feel it too. So, like Dad doesn't turn up to contact. Or they are embarrassed at school because they are not allowed to go on an excursion and everyone else is. Or whatever it is, you, I think more so than your own stress or physical pain from assaults or whatever, it's more watching the kids go through pain that is really hard about this job.

Interviewer: What's the hardest part of that?

Participant: When you can't change it. Yeah. So, I mean, when kids can't go home. Or when parents don't turn up to contact.

In her description, this participant reveals that she has the capacity to feel empathy for the young people without taking on their pain as her own. This is evidence of a self-authoring construction. Another participant, working in a supervisor role, talked about the challenge of seeing the staff in pain:

When you take it, you take it with you, like you take it, you breathe it day in and day out, and if you don't do anything about it then it has real implications ... compassion fatigue. It's been very hard so seeing the pain, understanding it, knowing where the young people and families are coming from and also where the staff are coming from, and then like, I think some of the things I've struggled with the most is actually seeing a change in the staff. These amazing, wonderful people who do amazing work and you see their personalities change ... but in the same way that you can't make a young person, you can't do the treatment, we also can't save the staff. That's often time the really hard part and you see it happening and you do your initial supervisions, you do your group supervisions, you do your 
International Journal of Child, Youth and Family Studies (2019) 10(2-3): 45-62

informal chats, you do your check-ins, but you can't stop it, and you have no control over it, so you provide the information, you provide the resources, you give them the pamphlets, you set up those kinds of things, but it doesn't mean that they're going to be okay.

Although challenged to deal with the pain of others, for self-authoring participants the challenge was not internal but was related to having empathy, and providing support, for the individuals who were in pain. They are able to do this because they were no longer embedded in the interpersonal. As stated by Kegan (1994),

When the self ... is bigger than those co-constructions and thus no longer identified with them the source of its own sense of continued well-being and integrity is not limited to its life within the shared reality of the relationship .... But if we neither identify with the internal registering of how the other feels nor ignore it, but are able instead to be in relationship to it, then we do not leave off caring for the other, we leave off being made up by our caring. We become able to do something with our caring for the other. (p. 126).

Dealing effectively with emotional pain requires an ability to acknowledge and move towards that pain (Kahn, 2005). Individuals who are self-authoring demonstrated the capacity to engage in this level of engagement, whereas those who were socialized identified moving away from others' pain in order to cope with their own.

\section{The Role of the Supervisor in the Provision of a Holding Environment: Absorption, Containment, Support, Challenge, and Continuity}

One of the key principles underlying constructive-developmental theory is that development is a lifelong process that occurs through ongoing interaction between an individual and the psychosocial environment (Kegan, 1982). Kegan refers to the psychosocial environment as a holding environment, a term originally conceptualized by Winnicott (1965) to describe the importance of the caregiver's physical and psychological holding in supporting an infant's development. According to Kegan (1982), holding does not only occur during infancy and it can include broader psychosocial contexts such as those comprised by co-workers, classmates, and friends. Individuals experience a succession of holding environments in their lifetime, and, for adults, the workplace is one of these holding environments (Kegan, 1994). From a constructivedevelopmental standpoint, the holding environment provides a balance of support and challenge to individuals that acknowledges where they are and facilitates movement to the next developmental order. Without adequate holding, individuals may have difficulty dealing with situations in which there is a mismatch between their meaning-making system and the demands of the environment, and they do not experience developmental growth. 
International Journal of Child, Youth and Family Studies (2019) 10(2-3): 45-62

Coping with the demands of the job, for individuals at all developmental orders, occurs within, and is influenced by, the organizational context. As stated by Kegan (1982), "Our wellbeing (or lack of it) is as much as anything a reflection on the quality of those most intimate 'supports' which, from the point of view of our current evolutionary truce, are confused with ourselves" (p. 193). Providing adequate holding to employees across developmental orders can be a tricky balance. "Environments that are weighted too heavily in the direction of challenge are toxic; they promote defensiveness and constriction. Those weighted too heavily toward support without adequate challenge are ultimately boring; they promote devitalization" (Kegan, 1994, p. 42).

In my research study (Modlin, 2018), the psychosocial elements of the organizational environment, consisting of co-workers, supervisors, and managers, were referenced repeatedly by participants. The importance, and type of, support required by each of these groups varied depending on the developmental order of the participant.

\section{Holding Socialized Practitioners}

At the socialized order, individuals look outside of themselves for answers and solutions and rely on expert authority to assist with decision-making. All participants in the study who were making meaning at the socialized order reported relying heavily on direction and guidance from their supervisors to help them cope with the demands of the job and, in some cases, to help promote growth. Supervision needed to be accepting and non-judgmental, and to provide a "safe place" where participants could talk about what was bothering them and receive constructive feedback and praise from supervisors.

When asked what would happen without the support and supervision they received, participants did not mince words. Their responses included: "That would be horrible. I would probably leave. I don't know how you could do it if you weren't supported. It would be very hard. It would, like, mentally would be a lot harder." "I don't know. I don't think I'd last. To be honest, I don't think I can do it all on my own. I think I would, I'd probably get dragged down or burn out quickly." One individual disclosed that she would "probably use a lot of sick leave, honestly, because I mean, that sucks". Another participant stated, "That's where a lot of burnout would probably come from if you're not supported." In describing what the ongoing support meant to her, she said, "The world. That allows me to go home to my own children at night and function as a normal human being."

Socialized participants also highlighted the importance of being noticed, acknowledged, and validated by senior management. This need to be seen is consistent with Kegan's (1982) contention that, to be responsive, a holding environment (in this case the organizational environment) must recognize and support individuals at all orders of development and recognize them for "who they are". Being acknowledged by senior management was identified by some participants as crucial to their own view of themselves as important and valuable employees. Without receiving that external acknowledgment individuals with a socialized mindset have 
International Journal of Child, Youth and Family Studies (2019) 10(2-3): 45-62

difficulty knowing how they are doing. In the midst of dealing with challenging situations with the young people, the absence of any external guidance leaves these practitioners feeling defeated.

In addition to support from supervisors and management, all participants at the socialized order, and those who were transitioning from socialized to self-authoring, cited support from their co-workers as pivotal to their ability to do the job. This aligns with their reliance on external resources and embeddedness in the interpersonal realm.

\section{Holding Self-Authoring Practitioners}

The self-authoring system is able to "relate to one's interpersonal relationships and intrapersonal states rather than be made up by them" (Kegan, 1994, p. 176). For self-authoring participants, coping was related to their ability to perform their jobs to their own standards. Unlike at the socialized order, those who are self-authoring are able to subordinate multiple or contradictory demands to a supervening principle, their own internal system of governance, which can regulate the demands (Kegan, 1994). When feeling overwhelmed, rather than automatically relying on others for direction, all self-authoring participants talked about their need to take control of the situation.

Instead of being shaped by outside events, self-authoring individuals have an internal system that "reconstructs and regulates them according to its own way of determining value" (Kegan, 1994, p. 173). When participants who were self-authoring did get triggered by something, they had the capacity to recognize what was happening and take control of their reaction. One participant identified that in these types of situations, he needs to "stop and think, breathe for a minute like ... this is why I'm feeling this way. I need to get past that and then deal with whatever it is that's just been said". In a similar vein, another participant described taking control of her own self-care, stating, "I hope that at this stage, I've learned some individual internalized coping skills. I have a really good support system and self-care plan for myself."

Unlike individuals at the socialized order, those who are self-authoring use relationships as a means of enriching their own understanding and experience - the process of working together provides a broader context for articulating, discussing, and challenging their own thoughts and ideas (Kegan, 1994). All participants who were self-authoring talked about support in terms of having someone they could go to as needed, to vent or bounce ideas off. Although the form of supervision and support that self-authoring participants identified needing was different than for socialized participants, their responses to the question about not having any support were very similar.

\section{Organizational Implications of the Study}

Just as child and youth care workers must provide holding for the young people in their care, so too must the organization provide holding for the practitioners. Interpersonal interactions between individuals of varying developmental capacities within an organization can help to 
broaden the perspectives of all employees, challenge them to experiment with new ways of thinking and behaving, and become a catalyst for growth (Kegan et al., 2001).

If the demands of child and youth care practice in residential care require self-authoring capacity and most practitioners enter the role at the socialized order, there is potential for considerable mismatch between the job demands and practitioners' capacity to meet them. When residential programs are set up on models that are over the heads of most practitioners working there, they may be destined to fail. The staff can become frustrated and confused, not understand what is expected of them, and, in the absence of clear direction and support, respond to the young people based on instinct and "common sense". Program drift and unsafe practice can occur. A supportive climate with a supervisor that is in tune with employees' developmental needs may buffer the demands of the job by providing practitioners with the necessary resources to effectively deal with the young people's challenging behaviours and pervasive pain, while an unsupportive climate may compound the challenges presented by the young people. A focused effort to provide socialized practitioners with the guidance, support, and acknowledgment they require, for example, can help ensure that the external source of authority to which they are aligned is not the young people. With an understanding of, and strategic focus on, transformational growth, the environment can provide the external supports needed for individuals to do the job effectively from their own meaning-making systems, while also promoting development to a more complex way of knowing. 
International Journal of Child, Youth and Family Studies (2019) 10(2-3): 45-62

\section{References}

Anderson-Nathe, B. (2010). Youth workers, stuckness, and the myth of supercompetence: Not knowing what to do. New York, NY: Routledge.

Anglin, J. P. (2002). Pain, normality and the struggle for congruence: Reinterpreting residential care for children and youth. Binghamton, NY: Haworth.

Berger, J. G. (2002). Exploring the connection between teacher education practice and adult development theory [Unpublished doctoral disseration]. Harvard University, Cambridge, MA.

Brendtro, L. (2004, January). From coercive to strength-based intervention: Responding to the needs of children in pain. Presentation with Charles Curie at Children \& Youth: Their Needs, Our Commitment conference, Alliance for Children and Families, Naples Beach, FL: No Disposable Kids, Inc. Retrieved from http://graingered.pbworks.com/f/Coercive to Strength-based.pdf

Cazabon, A. (2005). Wards of the Crown [DVD]. National Film Board of Canada.

Collins, S., \& Long, A. (2003). Working with the psychological effects of trauma: Consequences for the mental-health workers - a literature review. Journal of Psychiatric and Mental Health Nursing, 10, 417-424. doi:10.1046/j.1365-2850.2003.00620.x

Crenshaw, D., \& Garbarino, J. (2007). The hidden dimensions: Profound sorrow and buried potential in violent youth. Journal of Humanistic Psychology, 47(2), 160-174. doi: $10.1177 / 0022167806293310$

Drath, W. H. (1990). Managerial strengths and weaknesses as functions of the development of personal meaning. Journal of Applied Behavioral Science, 26(4), 483-499. doi: $10.1177 / 0021886390264006$

Figley, C. R. (Ed.). (1995). Compassion fatigue: Coping with secondary traumatic stress disorder in those who treat the traumatized. New York, NY: Brunner/Mazel.

Finlay, J. (2003). Crossover kids: Care to custody [Draft report]. Toronto, ON: Office of Child and Family Service Advocacy.

Frensch, K., Cameron, G., \& Adams, G. R. (2003). Treatment of choice or as a last resort? A review of residential mental health placements for children and adolescents [Partnerships for Children and Families Project]. Waterloo, ON: Wilfred Laurier University.

Kahn, W. A. (2005). Holding fast: The struggle to create resilient caregiving organizations. New York, NY: Brunner-Routledge. 
International Journal of Child, Youth and Family Studies (2019) 10(2-3): 45-62

Kegan, R. (1982). The evolving self: Problem and process in human development. Cambridge, MA: Harvard University Press.

Kegan, R. (1994). In over our heads: The mental demands of modern life. Cambridge, MA: Harvard University Press.

Lahey, L., Souvaine, E., Kegan, R., Goodman, R., \& Felix, S. (1988) A guide to the subjectobject interview: Its administration and interpretation. Cambridge, MA: The SubjectObject Research Group, Harvard Graduate School of Education.

Mattingly, M. (1981). Occupational stress for group care personnel. In F. Ainsworth \& L. Fulcher (Eds.), Group care for children: Concepts and issues. New York, NY: Tavistock Publications.

Modlin, H. (2018). Exploring the experiences of child and youth care workers in residential care through a constructive-developmental lens [Unpublished doctoral dissertation]. University of Victoria, Victoria, BC.

Moos, R. H. (2008). Work Environment Scale manual. Palo Alto, CA: Mind Garden.

Nouwen, H. (2017). You are the beloved: Daily meditations for spiritual living. New York, NY: Convergent.

Osofsky, J. D., Putnam, F. W., \& Leiderman, C. S. (2008). How to maintain emotional health when working with trauma. Juvenile and Family Court Journal 59(4), 91-102. doi:10.1111/j.1755-6988.2008.00023.x

Perry, B., \& Szalavitz, M. (2006). The boy who was raised as a dog and other stories from a child psychiatrist's notebook. New York, NY: Basic Books.

Phelan, J. (2009). The wounded healer as helper and helped: A CYC model. CYC-Online, 121. Retrieved from https://www.cyc-net.org/cyc-online/cyconline-mar2009-phelan.html

Popp, N., \& Portnow, E. (2001). Chapter three: Our developmental perspective on adulthood. In R. Kegan, M. Broderick, E. Drago-Severson, D. Helsing, N. Popp, \& K. Portnow, (Eds.), Towards a new pluralism in ABE/ESL classrooms: Teaching to multiple "cultures of mind." Cambridge, MA: National Centre for the Study of Adult Learning and Literacy.

Raychaba, B. (1993). Pain... lots of pain: Family violence and abuse in the lives of young people in care. Ottawa, ON: National Youth in Care Network.

Seti, C. L. (2007). Causes and treatment of burnout in residential child care workers: A review of the research. Residential Treatment for Children and Youth, 24(3), 197-229. doi:10.1080/08865710802111972 
International Journal of Child, Youth and Family Studies (2019) 10(2-3): 45-62

Smith, M. (2009). Rethinking residential child care: Positive perspectives. Bristol, UK: Policy.

Stamm, B. H. (2010). The concise ProQOL manual (2nd ed.). Pocatello, ID: ProQOL.org.

Strang, S. E., \& Kuhnert, K. W. (2009). Personality and Leadership Developmental Levels as predictors of leader performance. The Leadership Quarterly, 20, 421-433. doi:10.1016/j.leaqua.2009.03.009

Torbert, W. R., \& Livne-Tarandach, R. (2009). Reliability and validity tests of the Harthill Leadership Development Profile in the context of Developmental Action Inquiry theory, practice and method. Integral Review, 5(2), 133-151.

van Beinum, M. (2008). Mental health and children and young people in residential care. In A. Kendrick (Ed.), Residential child care: Prospects and challenges. London, UK: Jessica Kingsley.

Villegas-Reimers, E. (1988). Venezuelan adolescents' reasoning about responsibility (Unpublished doctoral dissertation). Harvard University, Boston, MA.

Whittaker, J. K., \& Pfeiffer, S. I. (1994). Research priorities for residential group care. Child Welfare: Journal of Policy, Practice, and Program, 73(5), 583-601.

Winnicott, D. (1965). The maturational process and the facilitating environment. New York, NY: International Universities Press. 